\title{
Aktualisasi Pendokumentasian Asuhan Kebidanan dengan Metode SOAP pada Praktek Mandiri Bidan (PMB)
}

\author{
Luh Mertasari ${ }^{1 *}$, Wayan Sugandini ${ }^{2}$ (iD) \\ ${ }^{1,2}$ Universitas Pendidikan Ganesha, Singaraja, Indonesia \\ *Corresponding author: Bidanmertasari80@gmail.com
}

\begin{abstract}
Abstrak
Proses pendokumentasian dalam praktik mandiri bidan masih minim dilaksanakan oleh beberapa bidan, hal ini dikarenakan oleh berbagai faktor seperti tidak da waktu untuk menyusun karna jumlah pasien yang cukup banyak, kurangnya tenaga kerja bidan, dan kurang mampunya bisan dalam menyusun pendokumentasian. Tujuan dari penelitian ini adalah untuk mengidentifikasi pendokumentasian SOAP pada praktek mandiri bidan (PMB) dalam melaksanakan asuhan kebidanan di Kabupaten Buleleng, Jenis penelitian deskriptif dengan pendekatan cross-sectional, dengan jumlah poupulasi sebanyak 400 orang. Penarikan sampel dilakukan dengan menggunakan teknik purposive sampling dan didaptkan 43 sampel. Teknik pengumpulan data dilakukan dengan menggunakan teknik observasi, dimana hasil penelitian kemudian dianalisis dengan analisis univariat. Berdasarkan hasil analisis penelitian didapatkan hasil bahwa pada ketersediaan formulir pendokumentasian asuhan kebidanan dengan metode SOAP dengan kategori cukup lengkap yaitu (53\%). PMB belum optimal dalam melakukan pencatatan pelayanan kebidanan. Kurang dari sebagian (47\%) PMB di kabupaten Buleleng yang melakukan Pencatatan/pendokumentasian pelayanan kebidanan dengan sangat baik. Sehingga dapat disimpulkan bahwa pendokumentasian pada PMB masih perlu ditingkatkan.
\end{abstract}

Keywords: Dokumentasi, SOAP, PMB

\section{Abstract}

The documentation process in the independent practice of midwives is still minimally carried out by some midwives, this is due to various factors such as not having time to compile due to a large number of patients, lack of midwifery workforce, and lack of ability in compiling documentation. The purpose of this study was to identify the documentation of SOAP in the independent practice of midwives (PMB) in carrying out midwifery care in the Buleleng Regency. This type of descriptive research with a cross-sectional approach, with a population of 400 people. Sampling was carried out using the purposive sampling technique and 43 samples were obtained. Data collection techniques were carried out using observation techniques, where the results of the study were then analyzed by univariate analysis. Based on the results of the research analysis, it was found that the availability of the midwifery care documentation form using the SOAP method was quite complete, namely (53\%). PMB has not been optimal in recording midwifery services. Less than half (47\%) of PMBs in the Buleleng district are very good at recording/documenting midwifery services. So it can be concluded that the documentation on PMB still needs to be improved.

Keywords: Documentation, SOAP, PMB

\section{Introduction}

Bidan merupakan salah satu tenaga kesehatan di Indonesia yang bertugas untuk memberikan pelayanan kesehatan secara mandiri kepada masyarakat sepanjang siklus kehidupan dalam bentuk pelayanan dalam fasilitas kesehatan Praktek Mandiri Bidan (PMB) (Marsaoly et al., 2019). PMB adalah kewenangan yang diberikan kepada seorang bidan yang telah memenuhi syarat untuk melakukan praktek mandiri sesuai dengan peraturan perundangundangan yang berlaku (Mertasari \& Sugandini, 2020; Noorbaya et al., 2019). Dalam kewenangan melakukan praktek mandiri, seorang bidan dapat melaksanakan perannya secara mandiri seperti memberikan pelayanan kebidanan pada ibu hamil, ibu bersalin, ibu nifas, bayi

$\begin{array}{lll}\text { History: } & & \text { Publisher: Undiksha Press } \\ \text { Received } & : \text { 21 Januari } 2021 & \text { Licensed: This work is licensed under } \\ \text { Revised } & : \text { 09 Februari } 2021 & \text { a Creative Commons Attribution 3.0 License } \\ \text { Accepted } & : \text { 16 Maret } 2021 & \text { CC (O) } \\ \text { Published } & : 25 \text { April } 2021 & \end{array}$


baru lahir, neonates, bayi balita, kesehatan perempuan dan Keluarga berencana (Khoiriyah et al., 2019). Bila ada permasalahan dalam memberikan asuhan yang tidak sesuai dengan kompetensi bidan maka bidan juga mempunyai otoritas untuk melakukan kolabirasi dan merujuk kasus asuhan yang dihadapi.

Dalam melakukan paktek mandiri seorang bidan selain harus memenuhi syarat pendidikan minimal bidan profesi, memenuhi syarat memiliki tempat praktek yang layak, dan fasilitas tempat praktek yang sesuai dengan peraturan, mampu mendokumentasikan asuhan kebidanan dan pelayanan kebianan yang diberikan kepada sasaran pelayanan kebidanan (ibu dan anak) dengan baik sesuai dengan pedoman pendokumentasian yang ada (Putriana, 2015). Namun pada kenyataannya pendokumentasian terkadang sering terabaikan karena dianggap menambah beban bagi bidan dalam melaksanakan prakteknya mengingat begitu banyaknya tugas yang harus diambil bidan (Yunie \& Chanty, 2016). Dari berbagai standar dalam melakukan praktek mandiri bidan, standar dokumentasi seringkali kurang mendapat perhatian bidan dalam menjalankan profesinya karena terkendala oleh waktu pendokumentasian yang cukup lama, menganggap bahwa pendokumentasian asuhan kebidanan pada saat pelasksanaan praktek mandiri akan menyita banyak waktu mengingat arus pasien yang cukup cepat pada saat jam praktek mandiri dan juga banyaknya kegiatan yang dilakukan oleh bidan (Palifiana, 2016). Selain itu pembuatan dokumentasi asuhan kebidanan yang idealnya harus dilakukan bersamaan dengan pelayanan atau pemberian asuhan terkadang tidak bisa dilakukan bersamaan karena minimnya tenaga dalam PMB.

Hal ini sejalan dengan hasil studi pendahuluan yang dilakukan pada PMB di wilayah puskesmas Buleleng I didapatkan data bahwa hanya sebagian kecil bidan yang mendokumentasikan asuhan kebidanan yang diberikan dalam pendokumentasian SOAP. Sebagian besar PMB memilih mengisi buku KIA, partograf dan kartu KB pada setiap pemberian asuhan kebidanan daripada menggunakan metod SOAP. Bidan hanya mengarsipkan laporan bulanan yang menjadi tanggung jawabnya untuk dilaporkan setiap akhir bulan ke puskesmas yang menaunginya. Adapun hasil wawancara terhadap penyebab kondisi tersebut adalah karena pasien banyak sehingga tidak sempat mendokumentasikan secara rinci, pasien sudah membawa ringkasan hasil dokumentasi asuhannya pada buku KIA, kartu KB, buku periksa dan catatan lain. Format pendokumentasian yang tersedia untuk satu orang pasien sangat banyak sehingga tidak efektif untuk mengisi semuanya, di tempat praktek PMB tidak menyiapkan format SOAP, format SOAP diisi hanya pada kasus tertentu dengan tidak lengkap, dan anggapan bahwa dokumentasi terperinci tidak begitu penting karena beberapa contoh pendokumentasian sudah disediakan oleh pemerintah seperti kartu KB dan buku KIA dan partograf.

Dari hasil visitasi yang dilakukan oleh tim visitator dari organisasi IBI dan dinas kesehatan dan badan perijinan dan penanaman modal kabupaten Buleleng sebagai prasarat mencari ijin PMB sebagian besar ditemukan pendokumentasikan yang dilakukan oleh bidan masih sangat minimal dan bidan masih memerlukan bimbingan dalam melakukan dokumentasi kebidanan terutama dalam pendokumentasian SOAP. Baik dalam bentuk bimbingan dalam pendokumentasian asuhan kebidanan dalam bentuk SOAP maupun dalam pendokumentasian asuhan dalam Kardek yang sudah tersedia. Bimbingan pendokumentasian SOAP yang diperlukan antara lain terkait dengan sistematika pelaporan, penentuan data focus, sistematis dan mudah dimengerti, penentuan diagnose sesuai dengan nomenklatur kebidanan, penatalaksanaan dan evaluasi. Selain itu praktek bidan juga belum terbiasa membuat catatan perkembangan pada pasien bersalin yang rawat inap setelah bersalin.

Padahal pada kenyataannya pendokumentasian kebidanan yang baik akan sangat membantu dalam melindungi bidan dari jeratan hukum apabila mendapat tuntutan dari klien atau pasien yang diasuh dikemudian hari (Herdiani \& Candratika, 2011). Sehingga pendokumentasian merupakan hal yang wajib dilakukan dimana dokumentasi kebidanan 
merupakan suatu catatan otentik dalam pemberian asuhan kebidanan yang dapat dijadikan bukti untuk melihat kualitas asuhan dan sebagai aspek legal suatu asuhan bila ada persoalan hukum. Selain bukti otentik yang sah, dokumentasi kebidanan dalam bentuk metode pendokumentasian SOAP (subyektif, Obyektif, Analisis, dan Penatalaksanaan) juga digunakan sebagai informasi tentang status kesehatan pasien pada semua kegiatan asuhan kebidanan yang diberikan kepada pasien dalam pelaksanaan praktek kebidanan termasuk dalam praktek mandiri bidan.

Bila dilihat dari segi manfaat pendokumentasian merupakan aspek legal yang bisa melindungi bidan dari tuntutan hukum, dari segi administrasi pendokumentasian asuhan kebidanan merupakan arsip atau bukti otentik dari segala tindakan bidan terhadap pasien/klien tersebut (Mertasari \& Sugandini, 2020). Disamping itu sesuai dengan fungsinya dokumentasi berperan sebagai pengumpul, penyimpan dan desiminasi informasi guna mempertahankan sejumlah fakta yang terus menerus pada suatu waktu terhadap sejumlah kejadian (Maritalia \& Rahmah, 2018). Dengan kata lain sebagai suatu keterangan baik tertulis maupun terekam, mengenai seluruh langkah menajemen kebidanan yang dilakukan baik pada pasien rawat jalan maupun rawat inap dan gawat darurat yang menjadi wewenang dan tanggung jawab bidan dalam melaksanakan prakteknya. Pendokumentasian dengan metode SOAP dapat menggambarkan proses menejemen asuhan kebidanan secara otentik, sistematis, sederhana dan mudah dimengerti.

Sehingga berdasarkan permasalahan yang ada dilapangan diupayakan untuk melaksanakan penelitian yang membahas mengenai "Aktualisasi Pendokumentasian Asuhan Kebidanan dengan Metode Soap pada Praktek Mandiri Bidan (PMB)" dengan tujuan untuk dapat mengidentifikasi tentang pelaksanaan pendokumentasian asuhan kebidanan dengan metode SOAP pada praktek mandiri bidan di Kabupaten Buleleng tahun 2020. Penelitian ini belum pernah dilakukan oleh peneliti sebelumnya sehingga adanya penelitian ini akan dapat membantu para bidan untuk lebih sadar akan pentingnya pendokumentasian asuhan kebidanan dan memahami cara penyusunan pendokumentasian asuhan kebidanan.

\section{Materials and Methods}

Jenis penelitian dalam penelitian ini adalah penelitian deskriptif dengan pendekatan evaluasi formatif untuk mendapatkan feedback dari suatu aktivitas dalam proses sehingga dapat digunakan untuk meningkatkan program atau produk (Arikunto, 2006). Metode pengumpulan data dilakukan berdasarkan pendekatan cross-sectional. Penelitian ini mengambil data tentang pendokumentasian pelayanan kebidanan oleh praktek mandiri bidan (PMB) pada tahun 2020. Variabel dalam penelitian ini adalah variable tunggal yaitu Pelaksanaan pendokumentasian asuhan kebidanan pada praktek mandiri bidan dengan metode SOAP. Penelitian ini berlokasi di Buleleng pada PMB yang berpraktek di Buleleng. Dengan jumlah populasi sebanyak 400 PMB. Penentuan jumlah sampel dengan cara purposif sampling dengan memilih 43 dari 400 PMB yang ada di kabupaten Buleleng yang pada saat penelitian melakukan praktek mandiri. Data yang dikumpulkan adalah data primer berupa hasil pendokumentasian SOAP pada saat PMB melakukan asuhan kebidanan. Pengumpulan data dilakukan dengan melaksanakan observasi dengan bantuan surveyor bidan Delima dengan isntrumen pengamatan yang sudah baku tentang pendokumentasian SOAP. Data hasil penelitian kemudian dianalisis menggunakan analisis univariat.

\section{Results and Discussion Result}

Hasil penelitian mengenai ketersediaan formulir Asuhan Kebidanan pada PMB di Kabupetan Buleleng pada tahun 2020 menunjukkan hasil bahwa ketersediaan formulir 
pendokumentasian pelayanan dengan kategori cukup lengkap dengan jumlah persentase sebesar 53\%. Secara lebih rinci hasil perhitungan persentase mengenai ketersediaan formulir pendokumentasian dapat dilihat pada tabel 1 .

Tabel 1. Deskripsi Ketersediaan Formulir Pendokumentasian Asuhan Kebidanan

\begin{tabular}{clccc}
\hline No & \multicolumn{2}{c}{ Ketersediaan formulir pendokumentasian } & n & \% \\
\hline 1 & Sangat lengkap & 13 & 30 \\
2 & Lengkap & 5 & 12 \\
3 & Cukup lengkap & 23 & 53 \\
4 & Kurang lengkap & 2 & 5 \\
5 & Sangat Kurang lengkap & - & - \\
\hline \multicolumn{2}{r}{ Total } & $\mathbf{4 3}$ & $\mathbf{1 0 0}$ \\
\hline
\end{tabular}

Selanjutnya pada hasil identifikasi tentang proses pelaksanaan pendokumentasian pelayanan kebidanan pada PMB di kabupaten Buleleng didapatkan hasil PMB belum optimal dalam melakukan pencatatan pelayanan kebidanan yakni kurang dengan jumlah persentase sebesar $47 \%$. Jumlah ini menunjukkan hanya kurang dari setengah bidan yang dapat menyusun pendokumentasian PMB dengan baik. Secara lebih rinci hasil mengenai pelaksanaan asuhan kebiadnan dengan metode SOAP pada PMB di Kabupaten Buleleng pada Tahun 2020 dapat dilihat pada tabel 2.

Tabel 2. Deskripsi Pelaksanaan Asuhan Kebiadnan dengan Metode SOAP

\begin{tabular}{clccc}
\hline No & Proses Pelaksanaan pendokumentasian dengan metode & N & \% \\
\hline 1 & SOAP & 20 & 47 \\
2 & Baik & & 15 & 35 \\
3 & Cukup Baik & 8 & 19 \\
4 & Kurang baik & & - & - \\
5 & Sangat Kurang baik & & - & - \\
\hline & & Total & $\mathbf{4 3}$ & $\mathbf{1 0 0}$ \\
\hline
\end{tabular}

\section{Discussion}

Temuan pertama, dalam penelitian ini menunjukkan bahwa pada ketersediaan formulir Asuhan Kebidanan pada PMB di Kabupaten Buleleng pada tahun 2020 cukup lengkap. Formulir yang disajikan oleh PMB Kabupaten Buleleng merupakan formulir dalam bentuk rekam medis. Rekam medis merupakan salah satu komponen penting dalam PMB hal ini dikarenakan rekam media sangat diperlukan dalam setiap sarana pelayanan kesehatan, baik ditinjau dari segi pelaksanaan praktik pelayanan kesehatan maupun dari aspek hukum, peraturan hukum berhubungan dengan pelaksanaan pelayanan kesehatan mencakup aspek hukum pidana, hukum perdata, dan hukum administrasi (Handiwidjojo, 2009). Dari aspek hukum rekam medis dapat digunakan sebagai alat bukti dalam perkara hukum (Susanto, 2011). Dalam memberikan pelayanan kebidanan idealnya PMB bidan Delima melengkapi semua Format pendokumentasian yang menjadi syarat dalam melakukan praktek dan dalam perekrutan bidan delima ketersediaan format pendokumentasian secara lengkap merupakan syarat wajib. Bidan Delima dalam memberikan pelayanan dan mendokumentasikan segala pelayanan kebidanan yang dilakukan mengacu kepada kebijakan dari pusat. Bidan delima wajib menyiapkan secara lengkap formulir pendokumentasian dan menyiapkan tambahan Formulir pendokumentasian yang lain sesuai dengan kebutuhan pelayanan. Selain itu sesuai dengan PMK 28 tahun 2017 bidan wajib melakukan praktek dengan prasarat praktek yang ada pada lampiran PMK 28 tersebut dimana salah satunya adalah tersedianya format 
pendokumentasian/pencatatan dan pelaporan.

Dalam proses rekam medis terdapat beberapa kegiatan yang harus dijalankan, antara lain: pencatatan, pengolahan dan penyimpanan. Setelah diolah, kemudian dilakukan penyimpanan dalam penyelengran rekam medis (Mertasari \& Sugandini, 2020). Cara penyimpanan ada dua yakni, cara sentralis dengan menyimpan rekam medis seorang pasien, baaik catatan poli klinis maupun catatan selama pasien dirawat yang dilakukan dalam satu kesatuan (Ritonga et al., 2020). Cara desentralisasi yaitu proses pemisahan antara rekam medis poliklinis dan rekam medis selama dirawat, rekam medis poliklinis disimpan disuatu tempat penyimpanan, sedangkan rekam medis pasien selama dirawat disimpan pada bagian pencatatan medis (Hidayati \& Dewi, 2018). Temuan kedua, dalam penelitian ini menunjukkan bahwa hanya kurang dari setengah bidan di kabupaten Buleleng yang mampu menyusun pendokumentasian dengan baik. Padahal pada kenyataannya dokumentasi kebidanan adalah bukti pencatatan dan pelaporan berdasarkan komunikasi tertulis yang akurat dan lengkap yang dimiliki bidan dalam melakukan asuhan kebidanan dan berguna untuk kepentingan klien, tim kesehatan, serta kalangan bidan sendiri (Puspitasari, 2019). Salah satu fungsi dokumentasi adalah sebagai aspek legal untuk menghindari tuntutan hukum dikemudian hari (Maritalia \& Rahmah, 2018). Bidan wajib mencatat setiap tindakan yang dilakukan didalam format pendokumentasian yang yang resmi, agar kuat dan terlindung dari jeratan hukum. Pelayanan yang ada dan diberikan oleh bidan delima sudah terstandar secara baku sesuai dengan standar yang ada pada Departemen Kesehatan RI, standar tersebut telah dituangkan dalam instrument Bidan Delima. Pada setiap proses persalinan yang berlangsung dibidan perlu diobservasi dan didokumentasikan dengan partograf, dan oservasi dengan partograf dimulai dari fase aktif persalinan..

Sesuai dengan ketentuan perijinan Praktek Mandiri Bidan wajib melaporkan segala pelayanan yang diberikan setiap bulan atau sewaktu-waktu bila keadaan mendesak, Pelaporan hasil pelayanan di DPS/BPS paling lambat dilakukan pada tanggal 7 bulan berikutnya. Bidan delima yang melaporkan hasil pelayanannya dengan formulir 4,5, 6 yang telah disediakan secara rutin yaitu $3 \mathrm{x}$ dalam setahun yaitu pada Trimester awal, trimester kedua dan trimester ke 3 tiap tahun. Sesuai dengan prasyarat pra kualifikasi Bidan Delima salah satunya adalah bidan harus mempunyai tenaga administrai dan mempunyai ruang administrai khusu agar dokumntasi tersimpan dengan rapi serta dengan manfaat dokumentasi sebagai aspek administratife pengarsipan sesuai dengan nomor register akan memudahkan dalam pencarian dokumen tersebut saat diperlukan (Sujianti \& Susanti, 2009).

\section{Conclusion}

Praktek mandiri bidan sebagian besar belum optimal dalam menyediakan formulir pendokumentasian asuhan kebidanan dengan SOAP, dimana ketersediaan formulir pendokumentasian asuhan kebidanan dengan metode SOAP dengan kategori cukup lengkap yaitu (53\%). PMB belum optimal dalam melakukan pencatatan pelayanan kebidanan. Kurang dari sebagian (47\%) PMB di kabupaten Buleleng yang melakukan Pencatatan/pendokumentasian pelayanan kebidanan dengan sangat baik.

\section{References}

Arikunto. (2006). Prosedur Penelitian Suatu Pendekatan Praktik. PT Rineka Cipta.

Handiwidjojo, W. (2009). Rekam medis elektronik. Jurnal EKSIS, 2(1). https://ti.ukdw.ac.id/ojs/index.php/eksis/article/view/383.

Herdiani, T., \& Candratika, M. (2011). Faktor-Faktor Yang Berhubungan Dengan Kelengkapan Pendokumentasian Asuhan Kebidanan Di Rsud Hasanuddin Damrah Manna. CHMK Midwifery Scientific Journal, 3(1), 59-66. http://cyber- 
chmk.net/ojs/index.php/bidan/article/view/760.

Hidayati, M., \& Dewi, R. M. (2018). Pengaruh Kelengkapan Formulir Resume Medis Rawat Inap Terhadap Mutu Rekam Medis Di RSUD Kabupaten Sumedang. Jurnal INFOKES, $2(3)$, $72-82$ http://journal.piksi.ac.id/index.php/INFOKES/article/view/46/23.

Khoiriyah, E., Nilasari, A., Kebidanan, A., \& Bintan, A. (2019). Asuhan Kebidanan Komprehensif Pada Ny. E Dan Bayi .E Di Bidan Praktik Mandiri Bidan R Kota Tanjungpinang. Jurnal Cakrawala Kesehatan, X(02), 142-150. https://ejurnal.anugerahbintan.ac.id/index.php/ck/article/view/30.

Maritalia, D., \& Rahmah, S. (2018). Pelatihan Pendokumentasian Asuhan Kebidanan Di Puskesmas Gandapura Kabupaten Bireuen Aceh-Indonesia. Jurnal Pengabdian Kepada Masyarakat, 1(1). http://103.215.72.91/index.php/pkm/article/view/27.

Marsaoly, S., Kemenkes, P., \& Kunci, K. (2019). Kinerja Bidan dalam Pertolongan Persalinan di Puskesmas Sulamadaha Performance of Midwives in childbirth Assistance at Sulamadaha Health. Jurnal Kesehatan Masyarakat, 9(2), 231-238. https://doi.org/10.31934/promotif.v9i2.976.

Mertasari, L., \& Sugandini, W. (2020). Evaluasi Pendokumentasian Pelayanan Kebidanan pada Praktek Mandiri Bidan ( PMB ) Bidan Delima Kabupaten Buleleng Tahun 2020. Seminar Nasional Riset Inovatif, 22-27. https://eproceeding.undiksha.ac.id/index. $\mathrm{php} / \mathrm{senari} / \mathrm{article} / \mathrm{view} / 2095 / 1376$.

Noorbaya, S., Johan, H., \& Reni, D. P. R. (2019). Studi Asuhan Kebidanan Komprehensif di Praktik Mandiri Bidan yang Terstandarisasi APN. Husada Mahakam: Jurnal Kesehatan, 4(7), 431. https://doi.org/10.35963/hmjk.v4i7.149.

Palifiana, D. A. (2016). Hubungan Pendidikan Bidan Dengan Penerapan Pendokumentasian Asuhan Kebidanan Pada Bidan Praktik Mandiri Di Kabupaten Bantul. Seminar Nasional Dan Internasional, 412-415. https://jurnal.unimus.ac.id/index.php/psn12012010/article/view/2127/2154.

Puspitasari, D. (2019). Pelaksanaan Dokumentasi Asuhan Kebidanan Terhadap Perlindungan Hukum Pasien Pada Bidan Praktik Mandiri (Studi di Kabupaten Cilacap). Jurnal Idea Hukum, 5(1), 1236-1253. https://doi.org/http://dx.doi.org/10.20884/1.jih.2019.5.1.103

Putriana, Y. (2015). Kompetensi Bidan Dalam Penanganan Awal Peb Dan Eklamsia Pada Bidan Praktik Mandiri. Jurnal Keperawatan, 11(1), 1907-0357. https://doi.org/http://dx.doi.org/10.26630/jkep.v11i1.526.

Ritonga, Z. A., Wannara, A. J., Studi, P., Medis, D. P., \& Medan, U. I. (2020). Faktor-faktor Penyebab Keterlambatan Waktu Penyediaan Rekam Medis Rawat Jalan Di RSU Madani Tahun 2019. Jurnal Ilmiah Perekam Dan Informasi Kesehatan Imelda, 5(1), 85-97. https://doi.org/https://doi.org/10.2411/jipiki.v5i1.341.

Sujianti, \& Susanti. (2009). Buku Ajar Konsep Kebidanan Teori dan Aplikasi. Mulia Medika.

Susanto, G. (2011). Sistem Informasi Rekam Medis Pada Rumah Sakit Umum Daerah ( RSUD ) Pacitan Berbasis Web Base. Jurnal Sentra Penelitian Engineering Dan Edukasi, 3(4), 18-24. https://doi.org/http://dx.doi.org/10.3112/speed.v3i4.922.

Yunie, \& Chanty. (2016). Gambaran Penerapan Pendokumentasian Asuhan Kebidanan Dibps Wilayah Kerja Kecamatan Singaparna Tahun 2015. Jurnal Kesehatan Bidkesmas Respati, 2(7), 63-71. https://doi.org/10.48186/bidkes.v2i7.74. 